\title{
Dignity, social investment and the Indigenous health gap
}

\section{Michael G Marmot}

\section{Government recognition is an important step: action is needed}

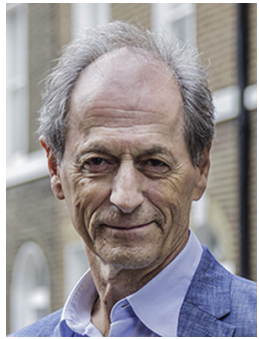

\begin{abstract}
n general, Australians are healthy. The data bear this out. A summary measure, life expectancy, puts Australian men in an elite group at the top of the global rankings just behind, in order, Hong Kong, Iceland, Switzerland, Italy, Israel and Sweden. Australian women, too, are near the top of the international life expectancy league. Hong Kong now exceeds Japan, and a few other countries enter, but Australian women are in an elite healthy group.
\end{abstract}

Not so Indigenous Australians. Their life expectancy trails nonIndigenous Australians by 10.6 years for men and 9.4 years for women. With a male life expectancy of 69 years, comparable figures come from Libya, Fiji and Trinidad and Tobago, countries at a much lower level of social and economic development than Australia. ${ }^{1}$

It is not difficult to ascribe the poor health of Indigenous Australians to poverty. A visit to less salubrious parts of cities, to the fringes of country towns or to remote communities reveals deprivation in the sea of plenty that is Australia. But data on infant mortality should give us pause. At about 6.3 of 1000 live births, although higher than among non-Indigenous Australians, it is remarkably low ${ }^{2}$ - lower than the average in a rich country such as the United States. The surprise comes because we think of infant mortality as a sensitive indicator of poverty, in the sense of material deprivation, or lack of access to medical care.

We need, then, to think of poverty among Indigenous Australians as not simply material deprivation, but depriving people of the freedom to lead a meaningful life. That deprivation starts in early childhood and continues throughout life. The clear implication is that action to reduce the health gap between Indigenous and nonIndigenous Australians must start "from preconception and the early years through school, providing a positive start to life, which of course opens opportunities for further study and employment. The high rates of suicide and disproportionately high rates of incarceration among our First Australians are issues that all governments, in partnership with community, need to work tirelessly to resolve" ${ }^{3}$

And such action must recognise that "[in] 2015, Indigenous children were almost twice as likely as non-Indigenous children to be developmentally vulnerable in health and wellbeing, social competence, communication and emotional maturity. This increases to nearly four times more likely to be developmentally vulnerable in language and cognitive skills". ${ }^{3}$

Further, improving education must acknowledge that "[school] attendance is affected by a range of underlying issues such as

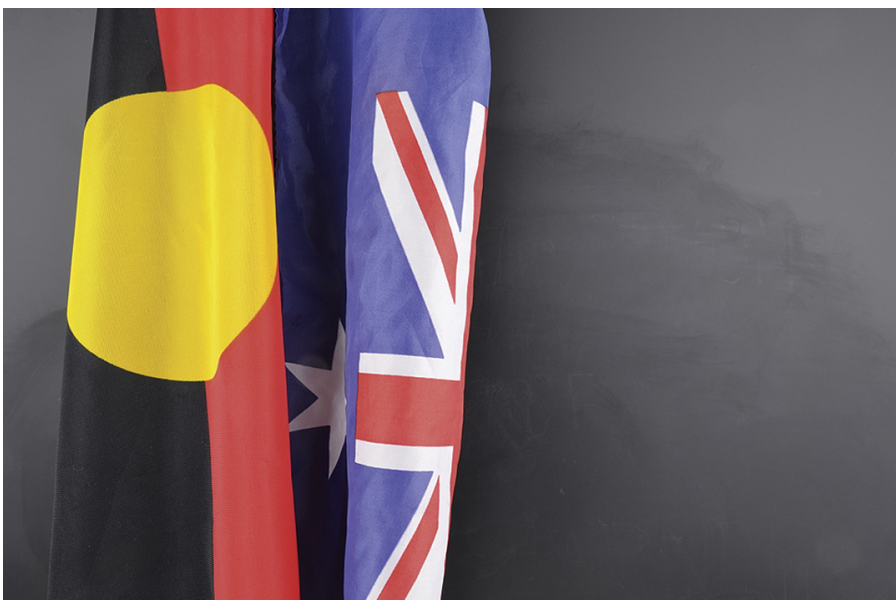

housing, health care, mental health issues, family violence and intergenerational unemployment".

These quotes could all have come from the report of the Commission on Social Determinants of Health (CSDH) ${ }^{4}$ had I edited it lightly to apply to the health gap in Australia. They are in fact from the Australian Prime Minister's Closing the Gap report 2017..$^{3}$ There is much more, including the need to recognise the importance of culture and to strengthen communities. All first rate. Exactly what is needed, in my view.

Then I read the Perspective by Hart and colleagues ${ }^{5}$ in this issue of the $M J A$, and I suffer a measure of cognitive dissonance. The authors write that there has been long recognition of the health gap by government in a series of reports, but action is not happening, or not quickly enough. They explicitly take their inspiration from the $\mathrm{CSDH}$, recognising that much of the Indigenous-non-Indigenous health gap must be attributed to differences beyond access to health care; and they lay great emphasis on education. I also note, from Laverty and colleagues, ${ }^{6}$ that the preconditions for educational success can be strengthened by culturally safe health care, attuned to social determinants and provided in health settings free of racism. They ascribe a leadership role to government for specific action to embed cultural safety in standards for safe, qualityassured clinical care.

Ever the optimist, I am cheered by the nature of the Prime Minister's report - sensitive recognition and open discussion of what is needed has to be an important step in progress. And progress there does seem to have been. The life expectancy gap has narrowed, although not fast enough. And to focus on education, the gaps are shamefully large still, but here, too, there is progress. From 2005 to 2015 there was a 93\% increase (from 8330 in 2005 to 16062 in 2015) in the number of Indigenous students in higher education award courses compared with $47 \%$ growth for all domestic students. ${ }^{3}$

Relieving poverty must create the conditions for people to lead lives they have reason to value. What this means in a particular 


\section{Embargo - Monday 3 July 2017 - 12.01am}

community must come from the community. It is a crucial part of empowerment and dignity. It is on this basis that necessary government investment must build.

Competing interests: No relevant disclosures.

Provenance: Commissioned; externally peer reviewed.

(c) 2017 AMPCo Pty Ltd. Produced with Elsevier B.V. All rights reserved.

1 United Nations Development Programme. Human development report 2016: human development for everyone. New York: UNDP; 2016. http://hdr.undp.org/sites/default/ files/2016_human_development_report.pdf (accessed Apr 2017).

2 Australian Institute of Health and Welfare. The health and welfare of Australia's Aboriginal and Torres Strait Islander peoples: 2015 (AlHW Cat. No. IHW 147). Canberra:
AlHW; 2015. http://www.aihw.gov.au/publication-detail/?id=60129550168 (accessed May 2017).

3 Department of the Prime Minister and Cabinet. Closing the Gap Prime Minister's report 2017. Canberra: Commonwealth of Australia; 2017. http://closingthegap.pmc.gov.au/sites/default/files/ctg-report-2017.pdf (accessed May 2017).

4 Commission on the Social Determinants of Health. Closing the gap in a generation: health equity through action on the social determinants of health. Final report of the Commission on Social Determinants of Health. Geneva: World Health Organization; 2008. http://apps.who.int/iris/ bitstream/10665/43943/1/9789241563703_eng.pdf (accessed May 2017).

5 Hart MB, Moore MJ, Laverty M. Improving Indigenous health through education. Med J Aust 2017; 207: 11-12.

6 Laverty M, McDermott DR, Calma T. Embedding cultural safety in Australia's main health care standards. Med J Aust 2017; 207: 15-16. 